\title{
A Very Damning Account
}

\section{An examination of the statements behind the question- 'Can social work survive?' \\ DAvid McGeE, Social Worker in Mental Health, Royal South Hants Hospital}

\begin{abstract}
A very damning account of the social work profession has been written by Brewer and Lait,' a profession which the authors perceive to be a ramshackle collection of idiosyncratic practitioners who clumsily bump and grind their way through the least fortunate sections of our society, doing untold harm. It would be gratifying to dismiss what they say; but social work after just over ten years in its present form is sorely in need of critical examination. We cannot ignore our critics, and it is imperative that we should put our house in order. Should social work survive is the real question being asked here-a political statement of a quite contentious nature.
\end{abstract}

Many attempts have been made to define social work roots, professional identity and tasks, for example, a recent article by F. Winckless in Community Care. ${ }^{2}$ Such accounts can often obscure, rather than clarify" the issues. P. Seed ${ }^{3}$ provides a good starting point in his historical account of the roots and growth of social work. It is clear from these references that Brewer and Lait did not begin here.

The introduction of Can Social Work Survive?* says that social work is still at a stage where more harm than good is being done. But, as the authors concede, doctors have been through such a stage themselves. Why then, should it follow that social work should be abolished or practised under medical supervision? If such views had prevailed during medicine's formative years we might never have had the comprehensive health service we have today.

Minimizing the effects of handicap is the business of social work. It is not necessarily a scientific business, although it benefits from scientific disciplines and thorough evaluation. Medicine, which has become, as Ian Kennedy ${ }^{4}$ reminds us, a scientific and technical pursuit, has not notably contributed to this minimizing of social handicap. It has principally concerned itself with the disease perspective and has abstracted illness from the individual in an attempt to treat it more effectively and objectively. Social work will always seek to take a more holistic view, placing the illness back in the context of the persons presenting it, then placing them back in the social situation in which they normally exist; finally, calculating how the incidence of illness will affect the individual's relationships within this system and how the system itself will function while coping with illness in the community of which it is part.

Through an extensive review of evaluative literature, Brewer and Lait have attempted to show that social work intervention tends to have a detrimental effect. They quote from twenty studies in the USA and UK, most of which cast a bad light on social work: they rely most heavily on studies

-For review of Can Social Work Survive? see page 171. by Fischer ${ }^{5}$ and Berg ${ }^{6 ; 7}$ which supposedly support their thesis.

An alternative view has been given by Pritchard, ${ }^{8}$ who points out that Fischer's work rests on dubious assumptions made by Eysenck in research undertaken between 1952 and 1964. Pritchard's work illustrates how the Leeds Truancy Study which comprises Bergs two studies has been misrepresented by Brewer and Lait.

The studies show that deferred sentences from the Magistrates Court, a juvenile equivalent of a suspended sentence, reduced truancy rates, whereas supervision orders undertaken by social workers had little effect on the rate, but had far-reaching effects in the long term, such as reducing the risk of youngsters coming into care or becoming court hardened. Brewer and Lait do not mention these effects.

It is interesting how disparate are the two presentations of the same work. I would recommend the reader to examine them side by side, one on pp. 150-55 in Can Social Work Survive? ${ }^{1}$ and p. 21 in Community Care, 11 December 1980. Since by Brewer and Lait's own admission these were the most significant studies we are left to assume that the others they mention do not serve their argument so well.

However, one study mentioned by Brewer and Lait does come out in favour of social work. Placed in a palliative fashion at the end of the chapter which attempts to dismantle the credibility of social work practice, Cooper's' study demonstrates that social workers are more effective in the treatment of chronic neurotics than are GPs. This study is a good argument for the attachment of social workers to family practices, as it indicates that the social work presence has a beneficial effect on the staff group generally as well as providing a better service to the clients.

I believe social work is most effective when practised as part of a multidisciplinary team, as I attempted to illustrate in my own article 'In practice'. ${ }^{10}$ Goldberg and Huxley ${ }^{11}$ put forward a similar view in their recent work:

'Unless the social work contribution is available in health settings, then the treatment of patients may well be more prolonged, and this will be to the detriment of the service as well as the patient. Social work involvement will not be effective if it is isolated and organized separately from other professional disciplines'.

Social workers ought to be good multidisciplinarians, taking a holistic view of systems and the way in which units interact within a given system. It follows that this has as many profound implications for the way a client and the problem presented are perceived, as there are for the way the agency delivers its service. The social work perspective can add something positive to both, as Cooper's study indicates. 
More evidence of the effectiveness of social work as an integral part of a multidisciplinary service can be found in Scott's ${ }^{12}$ recent work. This refreshing study shows how well psychiatrists, community nurses and social workers can work together when bringing their own differing skills into a multidisciplinary team, the purpose of which is to relieve suffering and to reduce the disturbance to normal life by obviating the need for a psychiatric admission wherever possible. This crisis intervention service has the added attraction of having proved itself to be cost-effective in as much as it saved over $£ 440,000$ a year on in-patient care at a cost of only $£ 45,000$ a year on overtime and extra mileage claims.

Work carried out in Southampton by Gibbons et al, ${ }^{13}$ although modest in its conclusions, shows that a taskcentred social work service delivered to self-poisoners is effective. While the study demonstrates social work to be no more effective than other methods of intervention, in reducing repetition it does improve the recipient's ability to cope with the social problems underlying the suicide attempt. There was no evidence to show that other methods do this, and again the social work input to this type of problem proved relatively inexpensive.

Creer and Wing ${ }^{14}$ say of schizophrenics that 'the social conditions in which patients live can to some extent determine the severity of disablement'. They argue for an integrated service which is geared to the needs of the sufferer of illness and those immediately affected, i.e., the family. A social work service is seen as a vital part of the network and crucial to the families long-term understanding of the situation with which it must ultimately cope.

The evidence the authors put forward concerning whether or not social workers were missed during the strikes in the late ' 70 s is, by their own admission, slender. It is also biased and judgmental, steeped in an attitude of 'making do'. As a society, we could make do without a great many things. We could leave to good will and public spiritedness a great many tasks which are currently legislated for. Unfortunately historical evidence suggests that this laissez-faire attitude to welfare is wanting.

Social work alone, like most other things in isolation will have a very limited effect on the situations in which its use is called for. There is little to gain from setting up in opposition to other professions; but a clearer idea of what we do that others do not will enable social work to take its place confidently in the multidisciplinary services which our clients are likely to demand and need throughout the ' 80 s.

It is necessary to point out that what I have said relates quite specifically to areas of work where doctors and social workers face the same problems. What Brewer and Lait fail to discuss in any depth is the considerable amount of central and local government legislation for which social workers are solely responsible. Doctors are seldom as involved in these areas, and I doubt if many would wish to be.

\section{REFERENCES}

'BreWEr, C. \& LArr, J. (1980) Can Social Work Survive? London: Maurice Temple Smith.

${ }^{2}$ WinckLess, F. (1981) Social work one foundation. Community Care, February 5.

${ }^{3}$ SeEd, P. (1973) The Expansion of Social Work in Britain. London: Routledge and Kegan Paul.

4KENNEDY, I. (1980) Unmasking medicine. Transcripts of The Reith Lectures in The Listener, November to December.

'FISCHER, (1978) Does anything work? Journal of Social Sciences Research, 1-3, 215-43.

'BERG, I. et al (1977) Truancy and the courts. Journal of Child Psychology and Psychiatry, 18.4, 359-66.

1 (1978) The effect of two randomly allocated court procedures on truancy. British Journal of Criminology, 18.3, 232-44.

'Prutchard, C. (1980) What is social work trying to do? Community Care, December 11.

'CoOper, B., Harwin, B. G., Depla, C. \& Shepherd, M. (1975) Mental health care in the community: An evaluative study. Psychological Medicine, 5.4, 372-80.

${ }^{10}$ McGee, D. (1980) In practice. Community Care, November 13.

"Goldberg, D. \& HuxLey, P. (1980) Mental Illness in the Community. London: Tavistock Publications.

${ }^{12}$ Scott, R. D. (1980) A family oriented psychiatric service to the London Borough of Barnet. Health Trends, October 12.

${ }^{13}$ GibBons, J. S., Butrer, J., URWin, P. \& GibBons, J. L. (1978) Evaluation of a social work service for self-poisoning patients. British Journal of Psychiatry, 133, 111-18.

${ }^{14}$ Creer, C. \& Wing, J. (1974) Schizophrenia at Home. London: Institute of Psychiatry.

\section{Errata}

We regret that certain errors occurred in the 'The College's Recommendations' for Mental Health Commissions for England and Wales (Bulletin, July, page 132). Under the section 'Functions of the Commissions', paragraph (d) should have read:

(d) Mental Health Commissions should have the duty to visit detained patients in hospital if requested by, or on behalf of, a detained patient or as often as they think appropriate. They should also similarly have a duty to visit patients that are subject to guardianship. On any such visit they should afford an opportunity on request for private interview to any such patient or where the patient is in a hospital to any other patient in that hospital.

Paragraph (h) should have read:

(h) Mental Health Commissions should advise for which treatments and under which circumstances second opinions should be obtained and arrange for such opinions to be provided. 